\title{
A Relevant Research between Climatic Factors and Regional Distribution and Development of Chinese Golf Courses
}

\author{
Huaxing Fang and Ge Chen \\ Department of Physical Education and Training, Wuhan Institute of Physical Education, Wuhan 430079, China
}

\begin{abstract}
On the basis of the distribution date of golf courses and golf driving ranges from all provinces, autonomous regions and municipalities in 2014 and the climatic factors from 1996 to 2013, mathematical statistics and comparative analysis are used to analyze and evaluate the climatic factor indicators influencing the golf courses distribution of all regions in China. Those indicators have differences of significance level on influencing the distribution of golf courses in each city of China.
\end{abstract}

Key words: Climatic factor, golf course, development, distribution.

\section{Introduction}

Climatic factor is one of the most important indicators to influence golf courses distribution, mainly manifested in precipitation, air temperature, relative humidity and city sunshine duration. According to "Chinese Statistical Yearbook", "Towards the White Paper" and TangGao website, this paper collected the data of climatic factors from 1996 to 2013, and the latest golf courses distribution data of all provinces [1-3], autonomous regions and municipalities in 2014. By the end of 2014, the golf courses were added up to 574, and the golf driving ranges reached 1,210 in China mainland except Tibet. Guangdong was in the first place with 83 courses and 189 golf driving ranges, followed by Beijing with 71 courses and 150 golf driving ranges, then was Shandong with 51 courses and 81 golf driving ranges, and then Hainan ranked in the fourth with 45 courses and 27 golf driving ranges, more than those in Tianjin and Liaoning located in more economically developed Beijing-Tianjin-Tangshan region and more than those in Shanghai, Jiangsu and Zhejiang located in Yangtze
River Delta region. According to the survey and what shows in "Towards the White Paper-Chinese Golf Industry Reports", the golf courses mainly distributed in the areas where economy is developed areas and climate is suitable to carry out the project [4-5]. The factor determined the development and regional distribution of golf courses is not single: certain government policies and economic conditions have huge influence on development, a good example like Dubai in the desert. And suitable climate is also an important factor of development, like Thailand and Hainan, where is underdeveloped but their golf courses also developed quite well. In this study, starting from the point of view of climatic factors, using comparative analysis to analyze and evaluate the climatic factor indicators influencing the golf course distributions from all provinces, autonomous regions, municipalities, in order to reveal the objective law that climatic factors influence the distribution of golf courses and provide the referential theory basis for the healthy development of golf.

Corresponding author: Huaxing Fang, M.S., research field: golf education and training. 


\section{Research Object and Methods}

\subsection{Research Object}

This study is based on all golf courses and golf driving ranges in all cities in China, provided by "Towards the White Paper" and the latest golf industry development report from Tanggao website. Relevant information is listed in Table 1.

\subsection{Research Methods}

Data collection method, mathematical statistics and comparative analysis method are used to statistically analyze and deal with the relative data with the statistical software SPSS16.0.

\section{Analysis and Selection on Climatic Factors Indicators}

\subsection{Average Temperature and Sunshine Duration}

From the point of lawn maintenance, more than one thousand acres of golf courses to maintain a long time green cover need to have a certain temperature and precipitation conditions. Since the temperature not only affects the turf quality and maintenance costs of golf courses, but also affects the outdoor development of golf. It is not suitable for golf when the temperature is below 10 degrees or above 30 degrees, so the annual temperature in one region determines the effective operating time of golf courses [6]. But from the influence factor of temperature, the impact of temperature changes in China on the development of golf industry can be summarized from north to south. The temperature conditions are more favorable for golf, the layout and development should be gradually increased from north to south. Considering that local temperature has influence on golf course maintenance, the most northern district should have no development or less development of golf [7]. Generally speaking, if monthly average sunshine duration is less than 90 hours in a region, it will not be conductive to the growth of grass and trees [8]. Whether a region is suitable to develop golf industry or not should take into account the impact of its local temperature and sunshine duration.

\subsection{Precipitation and Average Relative Humidity}

Water is one of the most important resources in golf courses maintenance. Taking the average daily water consumption of one golf course famous for its 18 holes in Shenzhen as an example, this course uses about 1500 tons of water one day, and about 200 tons is from city tap water, about 140 tons is from ground well water, about 1160 tons is from the storage and recharge of natural precipitation in ponds within golf course. It means that golf courses construction is closely related to regional precipitation $[9,10]$. According to the water demand in golf industry and the situation of annual precipitation in China, through the preliminary estimate of water usage on golf maintenance, there is crisis for golf courses water usage when the monthly average precipitation is lower

Table 1 Distribution data list of golf courses and golf driving ranges in all cities in china (except Tibet).

\begin{tabular}{|c|c|c|c|c|c|c|c|c|c|c|}
\hline & Beijing & Shanghai & Chongqing & Anhui & Fujian & Gansu & Guangdong & Guangxi & Guizhou & Hainan \\
\hline Golf Courses & 71 & 28 & 8 & 10 & 17 & 2 & 83 & 15 & 6 & 45 \\
\hline \multirow[t]{2}{*}{ Driving Ranges } & 150 & 77 & 17 & 21 & 41 & 7 & 189 & 20 & 8 & 27 \\
\hline & Hebei & $\begin{array}{l}\text { HeilongJ } \\
\text { ang }\end{array}$ & Ii Henan & Hubei & Hunan & Jiangsu & Jiangxi & Jilin & Liaoning & $\begin{array}{l}\text { Inner } \\
\text { Mongolia }\end{array}$ \\
\hline Golf Courses & 25 & 5 & 4 & 9 & 12 & 32 & 7 & 4 & 24 & 9 \\
\hline \multirow[t]{2}{*}{$\begin{array}{l}\text { Driving } \\
\text { Ranges }\end{array}$} & 14 & 14 & 31 & 47 & 38 & 104 & 21 & 20 & 49 & 17 \\
\hline & Ningxia & Qinghai & Shandong & Shanxi & Shaanxi & Sichuan & Tianjin & Xinjiang & Yunnan & Zhejiang \\
\hline Golf Courses & 4 & 1 & 51 & 8 & 6 & 13 & 17 & 4 & 31 & 23 \\
\hline Driving Ranges & 7 & 1 & 81 & 10 & 18 & 40 & 28 & 5 & 39 & 69 \\
\hline
\end{tabular}


than $50 \mathrm{~mm}$, but when the annual precipitation is up to $1000 \mathrm{~mm}$, it will be suitable for the development of golf industry. For now, the main resource of the golf course water usage is from natural precipitation, water storage in ponds, city water supply and exploitation of groundwater. If the precipitation in a region is too low, it will not only increase the water cost of golf courses, but also appear unreasonable due to taking up too much city water supply [7, 9]. The amount of precipitation in a region is related local average relative humidity. The greater the humidity in the air can ensure the moisture in lawn growth.

By the data from "Chinese Statistical Yearbook", due to the similarity of climatic factors from all provincial capitals and regions, precipitation, average temperature, average relative humidity and sunshine duration from capital cities, autonomous regions and municipalities are selected as indicators, which are from "Chinese Statistical Yearbook" in 1996-2013, to analyze the relationship between the climatic factors and golf course development and distribution.

\section{Result Analysis}

\subsection{Data Analysis of Golf Courses and Golf Ranges}

Golf courses and golf driving ranges correlation coefficient $\mathrm{R}$ equals 0.888 , and concomitant probability sig equals 0.000 . There is a strong positive linear correlation between golf courses and driving ranges (Fig. 1).

\subsection{Statistical Calculation and Analysis of Indicators} Data

After checking the climatic factor indicators from 1997 to 2014 of all provinces, autonomous regions and municipalities in China from "Chinese Statistical Yearbook", we obtained the climate date from 1996 to 2013, and the average values of indicators are shown in Table 2.

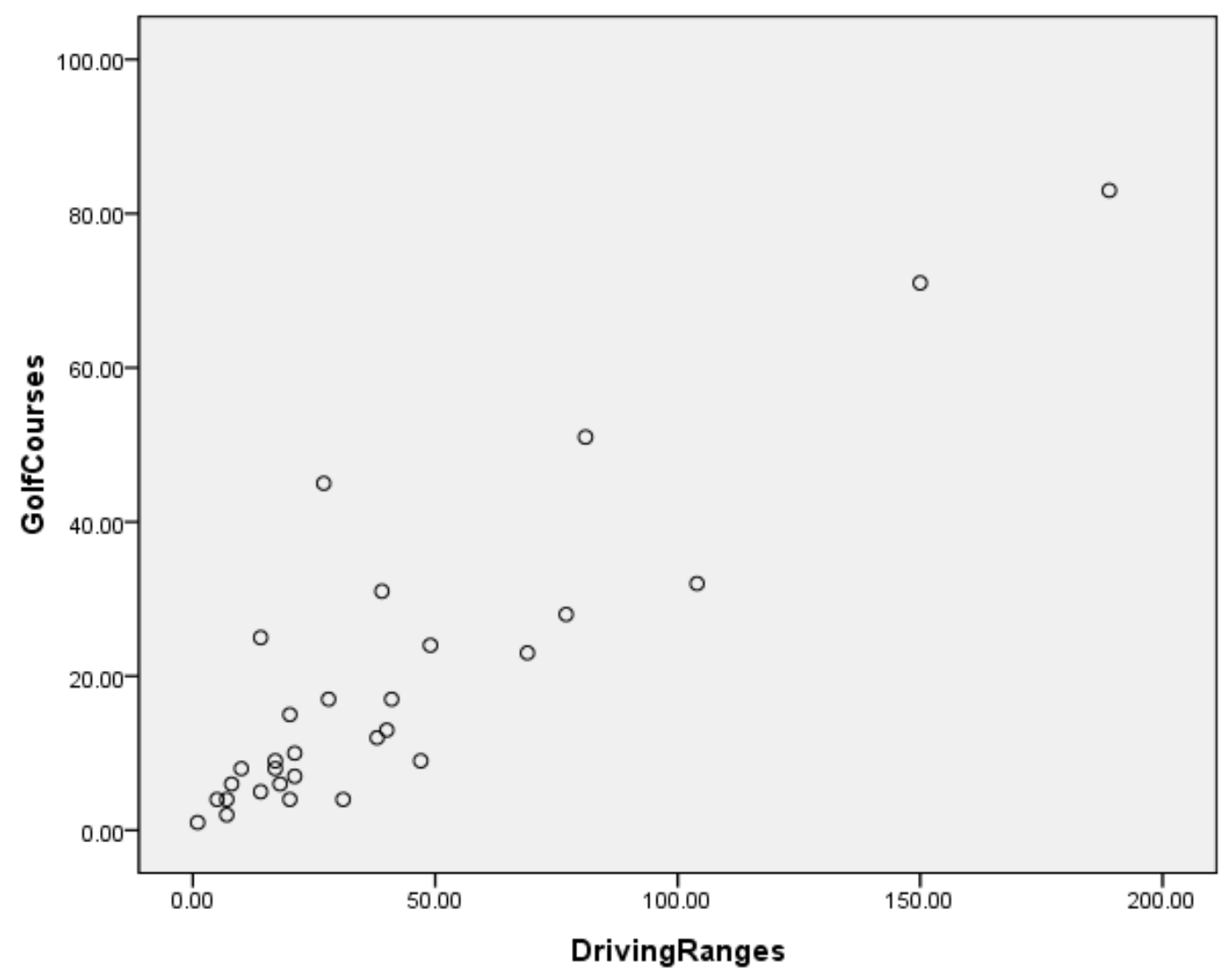

Fig. 1 Scatter plot of golf courses and golf driving ranges distribution in China. 
Table 2 List of annual climatic factor indicators average values of all provinces, autonomous regions and municipalities in China (1996 to 2013).

\begin{tabular}{|c|c|c|c|c|}
\hline & Precipitation $(\mathrm{mm})$ & Average Temperature $\left({ }^{\circ} \mathrm{C}\right)$ & Average Relative Humidity (\%) & Sunshine Duration (h) \\
\hline Beijing & 501.5 & 13.1 & 52.7 & 2450.8 \\
\hline Shanghai & 1161.5 & 17.2 & 72.3 & 1727.9 \\
\hline Chongqing & 1114.8 & 18.7 & 77.7 & 955.4 \\
\hline Hefei & 1000.2 & 16.6 & 73.8 & 1824.8 \\
\hline Fuzhou & 1415.8 & 20.5 & 72.6 & 1537.1 \\
\hline Lanzhou & 332.1 & 9.7 & 53.0 & 2504.9 \\
\hline Guangzhou & 1860.9 & 22.5 & 74.5 & 1550.5 \\
\hline Nanning & 1263.0 & 21.7 & 78.3 & 1504.7 \\
\hline Guiyang & 1068.2 & 14.8 & 77.8 & 973.8 \\
\hline Haikou & 1824.5 & 24.6 & 81.2 & 1789.3 \\
\hline Shijiazhuang & 540.4 & 14.3 & 57.5 & 2176.0 \\
\hline Harbin & 519.8 & 5.2 & 63.2 & 2295.2 \\
\hline Zhengzhou & 636.0 & 15.3 & 60.9 & 1835.3 \\
\hline Wuhan & 1261.3 & 17.5 & 73.6 & 1810.2 \\
\hline Changsha & 1423.0 & 17.9 & 75.8 & 1567.5 \\
\hline Nanjing & 1094.1 & 16.4 & 71.8 & 1915.3 \\
\hline Nanchang & 1633.1 & 17.8 & 73.7 & 1846.7 \\
\hline Changchun & 571.6 & 6.3 & 60.3 & 2554.3 \\
\hline Shenyang & 683.3 & 8.4 & 63.8 & 2355.3 \\
\hline Hohhot & 396.1 & 7.8 & 48.4 & 2661.1 \\
\hline Yinchuan & 184.0 & 10.1 & 51.4 & 2730.4 \\
\hline Xining & 425.9 & 5.9 & 56.9 & 2513.9 \\
\hline Jinan & 735.9 & 14.7 & 56.4 & 2170.6 \\
\hline Taiyuan & 425.5 & 10.9 & 55.1 & 2419.4 \\
\hline Xian & 551.3 & 14.3 & 63.4 & 1734.9 \\
\hline Chengdu & 834.4 & 16.6 & 77.0 & 928.3 \\
\hline Tianjin & 487.5 & 13.0 & 60.3 & 2233.0 \\
\hline Urumqi & 312.9 & 7.8 & 56.0 & 2647.5 \\
\hline Kunming & 966.1 & 16.0 & 67.8 & 2157.1 \\
\hline Hangzhou & 1417.7 & 17.5 & 72.5 & 1622.6 \\
\hline
\end{tabular}

From Table 1 and Table 2, there are 13 cities from major cities (1996 to 2013), where the annual precipitation average are greater than or equal to 1,000 mm, like Shanghai, Chongqing, Hefei, Fuzhou, Guangzhou, Nanning, Guiyang, Haikou, Wuhan, Changsha, Nanjing, Nanchang, and Hangzhou. Even though the annual precipitation average is not over $1,000 \mathrm{~mm}$ in Kunming and Chengdu, the annual precipitation is stable and relatively average each month. Therefore, it is suitable to develop golf industry in above 15 cities on local conditions. And the annual precipitation average is lower than 1,000 $\mathrm{mm}$ in these cities like Beijing, Lanzhou, Shijiazhuang, Harbin, Zhengzhou, Changchun, Shenyang, Hohhot,
Yinchuan, Xining, Jinan, Taiyuan, Xian, Tianjin, and Urumqi. Except that the annual precipitation average in Zhengzhou, Jinan and Shenyang is over $600 \mathrm{~mm}$, which can ensure the monthly precipitation average to reach about $50 \mathrm{~mm}$ without water crisis, other cities have water crisis in different degree, which lead to some problems of golf deformed development.

In Table 1 and Table 2, it shows that the annual average temperature is between $14.8^{\circ} \mathrm{C}$ (Guiyang) and $24.6^{\circ} \mathrm{C}$ (Haikou) over the years in 15 cities: Shanghai, Chongqing, Hefei, Fuzhou, Guangzhou, Nanning, Guiyang, Haikou, Wuhan, Changsha, Nanjing, Nanchang, Hangzhou, Kunming and Chengdu. In addition to these 8 central cities, like Nanjing, Hefei, 
Table 3 The correlation coefficient list between the amount of golf courses and golf driving ranges and the average values of annual climatic factor indicators.

\begin{tabular}{llllllll}
\hline & & A & B & C & D & E & F \\
\hline A & Pearson & 1 & 0.888 & 0.392 & 0.436 & 0.112 & -0.066 \\
& Sig & & 0.000 & 0.032 & 0.016 & 0.555 & 0.727 \\
B & Pearson & 0.888 & 1 & 0.394 & 0.377 & 0.145 & -0.139 \\
& Sig & 0.000 & & 0.031 & 0.040 & 0.444 & 0.463 \\
C & Pearson & 0.392 & 0.394 & 1 & 0.854 & 0.862 & -0.668 \\
& Sig & 0.032 & 0.031 & & 0.000 & 0.000 & 0.000 \\
D & Pearson & 0.436 & 0.377 & 0.854 & 1 & 0.777 & -0.728 \\
& Sig & 0.016 & 0.040 & 0.000 & & 0.000 & 0.000 \\
E & Pearson & 0.112 & 0.145 & 0.862 & 0.777 & 1 & -0.860 \\
& Sig & 0.555 & 0.444 & 0.000 & 0.000 & & 0.000 \\
F & Pearson & -0.066 & -0.139 & -0.668 & -0.728 & -0.860 & 1 \\
& Sig & 0.727 & 0.463 & 0.000 & 0.000 & 0.000 &
\end{tabular}

A: amount of golf courses; B: amount of golf driving ranges; C: precipitation; D: average temperature; E: average relative humidity; F: sunshine duration.

Shanghai, Chengdu, Hangzhou, Changsha, Wuhan and Nanchang, the temperature is low in January and February but too high in July and August, which have some effect on golf. While in the other 8 cities, the temperature is stable, which is suitable to develop golf industry. By contrast, the annual average temperature is between $5.2^{\circ} \mathrm{C}$ (Harbin) and $15.3^{\circ} \mathrm{C}$ (Zhengzhou) over the years in other 15 cities: Beijing, Lanzhou, Shijiazhuang, Harbin, Zhengzhou, Changchun, Shenyang, Hohhot, Yinchuan, Xining, Jinan, Taiyuan, Xian, Tianjin and Urumqi, and the average temperature is below $10^{\circ} \mathrm{C}$ in Lanzhou, Harbin, Changchun, Shenyang, Hohhot, Xining and Urumqi, which lead to the 15 cities in north close courses every year in winter, and the closing time lasts 5 months in Lanzhou, Harbin, Changchun, Shenyang, Hohhot, Xining and Urumqi.

From Table 1 and Table 2, in the 15 cities where the conditions of precipitation and temperature are superior, there are 339 golf courses and 668 golf driving ranges, accounting for $59.1 \%$ and $55.2 \%$ of the national total, respectively. While in the 15 cities in the north, the amount of golf courses and golf driving ranges account for $40.1 \%$ and $44.8 \%$ of the national total, respectively. And in Beijing, Shandong, Tianjin, Hebei and Liaoning located in developed economic regions of Jin-Jing-Tang, there are 118 golf courses and 332 golf driving ranges accounting for $20.6 \%$ and $26.6 \%$ of the national total, $50.2 \%$ and $59.4 \%$ of the total of the 15 cities in the north, respectively. The main reason why this happened is the developed economy in Jin-Jing-Tang regions.

According to the data from Table 1 and Table 2, the correlation coefficient Pearson between golf courses and golf driving ranges and each indicator are calculated (Table 3).

\section{Conclusions}

From Table 3, it is found that the correlation coefficient between golf courses and golf driving ranges is 0.888 , concomitant probability is 0.000 less than $P=0.05$, and there is high correlation. The golf courses and golf driving ranges have a significant correlation with precipitation and average temperature: When $P$ is less than 0.05 , the correlation with average relative humidity and sunshine duration is not significant; when $P$ is greater than 0.05 , it means that in climatic factors, the effect of precipitation and temperature on the development and distribution of golf courses is very significant, while the effect of average relative humidity and sunshine duration on the development and distribution of golf courses is not 
significant. Thus, the main indicators in climatic factor influencing the development and distribution of golf courses are precipitation and temperature. The distribution of golf courses mainly appear much in southeast and less in northwest, much in coastal areas and less inland, much in areas with superior climate conditions and less in areas with poor climate conditions. Most golf courses intensive areas to the south of Qinling Mountains and Huaihe River are with superior climate conditions, abundant precipitation and warm temperature, which ensure the longer business hours of full year and are suitable to develop golf industries, therefore, government should relax the policy, develop tourism resources and make full use of wasteland to develop golf courses in those regions. However, the areas to the north of Qinling Mountains and Huaihe River should respect its natural conditions. And for developed Jin-Jing-Tang region, government should take the sustainable development measures to develop no or less golf industry.

\section{References}

[1] National Bureau of Statistics of China. 2012. Chinese Statistical Yearbook: China's Major Cities 1997-2014 Climatic Factors Data. Accessed September 9, 2015. http://www.stats.gov.cn.

[2] He, G. M. 2013. A Case-Study Course for Applied Statistics-In SPSS for the Calculation Tool. Wuhan: HuaZhong University of Science \& Technology Press, 178-218.

[3] TangGao. 2015. China Golf Course, Golf Driving Range Data. Accessed September 12, 2015. http://www.golf998.com/golf_drill.php.

[4] Lian, Y. Q., and Zhang, H. W. 2011. "Comparative Study of Development of Golf in China and New Zealand." Journal of Wuhan Institute of Physical Education 2: 34-7.

[5] Shao, X. Y., Chen, X. R., and Mao, Z. M. 2010. "Social Characteristics of Golf Participants and Affect Factors of Choosing Golf Club in China." Journal of TUS 25: 60-3.

[6] He, M., Chen, Y. B., and Rao, Y. 2011. "An Analysis on the Factors Affecting the Regional Development and Distribution of Golf Courses." Journal of Beijing Sport University 1: 122-5.

[7] Han, L. B., and Zhou, G. Q. 2012. Introduction to Golf. Beijing: Tourism Education Press, 15-21.

[8] Liu, F. Z. 2014. "The Geographical Distribution of Chinese Golf." Contemporary Sports Technology 4:181-2.

[9] Shen, K. Y., and Liu, M. Y. 2012. "Environmental Ethics of the Sustainable Development of Golf Industry." Journal of Chengdu Sport University 11: 26-30.

[10] Yu, X. P., and Xia, H. S. 2004. "Comparison of Chinese and Foreign Golf Club Developmental Situation and Prediction." Journal of Physical Education 11: 136-8. 